\title{
Identification of Trichoderma, a Competitor of Shiitake Mushroom (Lentinula edodes), and Competition between Lentinula edodes and Trichoderma species in Korea
}

\author{
Chang Sun Kim ${ }^{1,2}$, Myung Soo Park ${ }^{3}$, Seon Cheol Kim ${ }^{4}$, Nitaro Maekawa ${ }^{5}$ and Seung Hun Yu${ }^{1 *}$ \\ ${ }^{1}$ Laboratory of Plant Pathology, College of Agriculture and Life Sciences, Chungnam National University, Daejeon 305-764, Korea \\ ${ }^{2}$ The Course of Bioenvironment Science, The United Graduate School of Agricultural Sciences, Tottori University, Tottori 680- \\ 8553, Japan \\ ${ }^{3}$ Bio-Control Research Team, Chemical Biotechnology Research Center, Korea Research Institute of Chemical Technology, \\ Daejeon 305-600, Korea \\ ${ }^{4}$ National Forestry Cooperatives Federation, Forest Mushroom Research Institute, Yeoju 469-803, Korea \\ ${ }^{5}$ Fungus/Mushroom Resource and Research Center, Tottori University, Tottori 680-8553, Japan \\ (Received on February 7, 2011; Revised on February 1, 2012; Accepted on February 15, 2012)
}

During investigating of shiitake mushroom competitors, 289 isolates of Trichoderma spp. were collected from shiitake mushroom farms in different districts and the Forest Mushroom Research Center of Korea, among which 29 representative strains were selected. Based on the DNA sequences of the rpb2 and tef1 genes and the ITS rDNA, and their morphological characteristics, they were identified as $T$. atroviride, $T$. citrinoviride, $T$. harzianum, T. longibrachiatum, and two undescribed species, Trichoderma spp. 1 and 2, which are considered to be the candidate of new species. Competition tests between Lentinula edodes (Sanjo302) and the Trichoderma species indicated that the six species of Trichoderma were significantly different from each other in terms of their ability to invade the mycelial blocks of shiitake. In both of dual cultures on potato dextrose agar and sawdust media, Trichoderma spp. 1 and 2 strongly invaded the mycelial blocks of shiitake. Our results suggest that the two Trichoderma species may cause potentially serious economic losses in shiitake cultivation of Korea.

Keywords : competition test, ITS, phylogenetic analysis, $r p b 2$, tef1

Shiitake mushrooms (Lentinula edodes) are widely cultivated as a food source in East Asia and are dried and exported to many countries because of its special flavor and aroma (Chen, 2005; Luo, 2004). Recent research has indicated that the shiitake mushroom also has useful clinical effects, including an immunostimulant (Yamamoto et al.,

\footnotetext{
*Corresponding author.

Phone) +82-42-821-5762, FAX) +82-42-823-8679

E-mail)shunyu@cnu.ac.kr
}

1997). In Korea, the consumption of shiitake mushrooms is increasing annually since 1999, and there are now about 20 cultivars of shiitake, which were promoted and disseminated by the Forest Mushroom Research Center.

The genus Trichoderma is one of the most important pathogens in the cultivation of the shiitake mushroom, and often causes severe damage during its production (Miyazaki et al., 2009). Trichoderma species mainly attack the mycelia of $L$. edodes in bed logs and sawdust cultures. The identification of Trichoderma at the species level has proved difficult because of their interspecific morphological similarities (Chaverri and Samuels, 2003). It led to the establishment of "aggregate" species concept by Rifai (1969) that all Trichoderma species could be distinguished to nine aggregates. Later, Bissett (1984, 1991a, b, c) established a new system of Trichoderma classification based on the branching pattern of conidiophores and the characteristics of phialides and conidia. After the introduction of molecular methods in Trichoderma taxonomy, the species concept of Trichoderma has changed dramatically (Chaverri and Samuels, 2003; Jaklitsch, 2009). In addition, the phylogenetic data helped to establish the relationship between anamorph Trichoderma and their related teleomorph Hypocrea (Chaverri and Samuels, 2003; Samuels et al., 1998, 2002).

In recent years, Park et al. $(2005,2006)$ identified seven distinct species of Trichoderma from that Trichoderma isolates from green mold of oyster mushroom were identified as seven distinct species (T. pleuroticola, T. pleurotum, T. atroviride, T. citrinoviride, T. harzianum, T. longibrachiatum and $T$. virens). However, little is known about the species of Trichoderma associated with the green mold observed on the shiitake mushrooms in Korea, and only five species of Trichoderma (T. citrinoviride, T. harzianum, T. polysporum, T. longibrachiatum and T. viride) were 
reported (Anonymous, 2009; Kim et al., 2012). In case of Japan, most of Trichoderma species identified by morphological methods or based on internal transcribed spacer (ITS) sequences (Hashioka, 1973; Miyazaki and Tsunoda, 2003; Miyazaki et al., 2009; Tokimoto and Komatsu, 1975; Tokimoto, 1985; Watanabe et al., 2005). The use of phylogenies based on single gene sequences is now generally discredited, especially the ITS regions of the ribosomal RNA genes, because some fungi have been shown to contain paralogous copies of these sequences (O'Donnell et al., 1998; Lieckfeldt and Seifert, 2000). Therefore, Taylor et al. (1999) proposed basing phylogenetic species concepts on a concordance multigene approach. In this study we used the sequences of three genes for the phylogenetic analysis: ITS, rpb2 (RNA polymerase II), and tefl (translation elongation factor 1- $\alpha$ ).

This study was conducted to identify these Trichoderma species as shiitake mushroom competitors, based on molecular and morphological characteristics. A competition test between $L$. edodes and Trichoderma species was also performed in the laboratory.

\section{Materials and Methods}

Strains and grouping. In total, 289 of Trichoderma isolates were collected from shiitake mushroom farms from different districts and the Forest Mushroom Research Center in Korea. Trichoderma isolates were separated into about 20 groups based on their culture characteristics on potato dextrose agar (PDA) for 10 days at $25^{\circ} \mathrm{C}$, and then 29 representative strains were selected from the groups based on locality of Korea for analysis. The reference strains and isolates examined are listed in Table 1, with their NCBI (National Center for Biotechnology Information) GenBank accession numbers.

DNA isolation. The isolates were grown in shaken liquid culture in potato dextrose broth for $3-4$ days at $25^{\circ} \mathrm{C}$. The mycelia were collected from the cultures by filtration and then transferred to $1.5 \mathrm{ml}$ tubes. These samples were frozen at $-70^{\circ} \mathrm{C}$. The DNA was extracted with the method of Cubero et al. (1999).

PCR amplification and sequencing. For the amplification of ITS, $r p b 2$, and tefl gene, three different primer sets were used; ITS5 and ITS4 (White et al., 1990), fRPB2-5F and fRPB2-7cR (Liu et al., 1999), and EF1-728F (Carbone and Kohn, 1999) and tefl-rev (Samuels et al., 2002), respectively. The PCR mixtures contained 0.5 pmol of each primer, $0.25 \mathrm{mM}$ dNTPs, $10 \mathrm{mM}$ Tris- $\mathrm{HCl}, 50 \mathrm{mM} \mathrm{KCl}$, $1.5 \mathrm{mM} \mathrm{MgCl}_{2}, 2.5 \mathrm{U}$ of Taq DNA polymerase, and $15 \mathrm{ng}$ of template DNA. The PCR cycling conditions for ITS and tefl gene were as follows: an initial denaturation step at $94^{\circ} \mathrm{C}$ for $10 \mathrm{~min}$, followed by 30 cycles of $94^{\circ} \mathrm{C}$ for $30 \mathrm{~s}$, $55^{\circ} \mathrm{C}$ for $30 \mathrm{~s}$, and $72^{\circ} \mathrm{C}$ for $60 \mathrm{~s}$; with a final elongation step at $72^{\circ} \mathrm{C}$ for $10 \mathrm{~min}$. For $r p b 2$ gene, the number of cycles and annealing temperature were respectively modified to 40 cycles and to $50^{\circ} \mathrm{C}$.

The PCR products were purified using a Wizard PCR Preps DNA Purification System (Promega, Madison, WI, USA). The purified double-stranded PCR fragments were directly sequenced with the BigDye Terminator Cycle Sequencing Kit (Applied Biosystems, Forster City, CA, USA), according to the manufacturer's instructions. The same primer sets used for PCR amplification were used to sequence both DNA strands. In the case of $r p b 2$ gene, two additional internal primers, RPB-432F and RPB-450R (Degenkolb et al., 2008), were used for the sequencing reactions. Gel electrophoresis and data collection were performed on an ABI Prism 310 Genetic Analyzer (Applied Biosystems).

Phylogenetic analysis. To determine the phylogenetic positions of the Trichoderma isolates, sequence alignments of the three gene fragments from 69 isolates of Trichoderma species, including 29 Korean isolates and 40 reference strains of sequences retrieved from GenBank, were analyzed with Neighbor-Joining and Bayesian inference (Table 1). The sequences were proofread, edited, and merged into comparable sequences using the PHYDIT program version 3.2 (Chun, 1995; available at http://plaza,sun,ac.kr/ $\sim$ jchun/phydit). The DNA sequences were aligned with Clustal X 1.81 (Thompson et al., 1997), and then visually corrected with a text editor. Ambiguously aligned regions were excluded from subsequent analyses. NJ tree were constructed using PAUP version 4.0b10 (Swofford, 2003) using the Kimura 2-parameter model. Bootstrap support (BS) values for nodes were computed from 1000 replicates for NJ analyze (Jeon et al., 2010). The general time-reversible model, under the assumption of a discrete gammashaped rate variation with a proportion of invariable sites $(\mathrm{GTR}+\mathrm{I}+\mathrm{G})$, was estimated as the best-fit likelihood model for the combined-sequences dataset. Bayesian analyses were conducted with MrBayes 3.1.2 (Ronquist and Huelsenbeck, 2003). Posterior probabilities (PP) were approximated with the metropolis-coupled Markov chain Monte Carlo method. Two parallel runs were conducted with one cold and three heated chains for 5 million generations, starting with a random tree. The three chains were heated at 0.2 for the combined-sequences dataset (the heats for cold chain 1 and heated chains 2,3 , and 4 were 1.00 , $0.83,0.71$, and 0.63 , respectively). The trees were saved to a file every 100th generation. We deemed that the two runs had reached convergence when the average standard 
Table 1. Information of Trichoderma isolates analyzed in this study

\begin{tabular}{|c|c|c|c|c|c|c|}
\hline \multirow{2}{*}{ Species } & \multirow{2}{*}{ Locality } & \multirow{2}{*}{ Substrate } & \multirow{2}{*}{ Strain No. } & \multicolumn{3}{|c|}{ GenBank accession numbers } \\
\hline & & & & ITS & $r p b 2$ & tef1 \\
\hline T. aggressivum & - & - & DAOM 100525 & AF057600 & AF545541 & AF348095 \\
\hline T. arundinaceum & - & - & CBS $119575 \mathrm{~T}$ & AY154921 & EU338303 & EU338275 \\
\hline \multirow[t]{9}{*}{ T. atroviride } & - & - & CBS 142.95 & AF456917 & EU341801 & AF456891 \\
\hline & Yeoju, Gyeonggi & Bed log & CNU N006 & HM769740 & HM920159 & HM920188 \\
\hline & Yeoju, Gyeonggi & Bed log & CNU N016 & HM769741 & HM920160 & HM920189 \\
\hline & Gumi, Gyeongbuk & Bed log & CNU N020 & HM769742 & HM920161 & HM920190 \\
\hline & Youngdong, Chungbuk & Bed log & CNU N022 & HM769743 & HM920162 & HM920191 \\
\hline & Gumi, Gyeongbu k & Bed log & CNU N088 & HM769744 & HM920163 & HM920192 \\
\hline & Cheongju, Chungbuk & Bed log & CNU N112 & HM769745 & HM920164 & HM920193 \\
\hline & Yeoju, Gyeonggi & Bed log & CNU N121 & HM769746 & HM920165 & HM920194 \\
\hline & Gongju, Chungnam & Bed log & CNU N192 & HM769747 & HM920166 & HM920195 \\
\hline \multirow[t]{2}{*}{ T. brevicompactum } & - & - & CBS $109720 \mathrm{~T}$ & - & EU338317 & EU338299 \\
\hline & - & - & CBS 121154 & EU338330 & - & - \\
\hline \multirow[t]{6}{*}{ T. citrinoviride } & - & - & DAOM 139758 & EU330960 & EU338338 & EU338334 \\
\hline & Jangsu, Jeonbuk & Bed log & CNU N066 & HM769748 & HM920167 & HM920196 \\
\hline & Gangneung, Gangwon & Bed log & CNU N114 & HM769749 & HM920168 & HМ920197 \\
\hline & Goheung, Jeonnam & Bed log & CNU N152 & HM769750 & HM920169 & HM920198 \\
\hline & Goheung, Jeonnam & Bed log & CNU N153 & HM769751 & HM920170 & НМ920199 \\
\hline & Yeoju, Gyeonggi & Sawdust & CNU N262 & HM769752 & HM920171 & HМ920200 \\
\hline T. erinaceus & - & - & DAOM 166121 & DQ109534 & EU248604 & DQ109547 \\
\hline T. hamatum & - & - & DAOM 167057 & Z48816 & AF545548 & AY750893 \\
\hline \multirow[t]{12}{*}{ T. harzianum } & - & - & IMI 393966 & AF443915 & AY391925 & - \\
\hline & - & - & CBS 226.95 T & - & - & AF348101 \\
\hline & Yecheon, Gyeongbuk & Bed log & CNU N034 & HM769730 & HМ920149 & HМ920178 \\
\hline & Yeoju, Gyeonggi & Bed log & CNU N072 & HM769731 & HM920150 & HM920179 \\
\hline & Gongju, Chungnam & Bed log & CNU N143 & HM769732 & HM920151 & НМ920180 \\
\hline & Yeoju, Gyeonggi & Bed log & CNU N169 & HM769733 & HM920152 & HМ920181 \\
\hline & Hwacheon, Gangwon & Bed log & CNU N171 & HM769734 & HM920153 & HM920182 \\
\hline & Yecheon, Gyeongbuk & Bed log & CNU N180 & HM769735 & HM920154 & HМ920183 \\
\hline & Gumi, Gyeongbuk & Bed log & CNU N185 & HM769736 & HM920155 & HM920184 \\
\hline & Gongju, Chungnam & Bed log & CNU N202 & HM769737 & HM920156 & HM920185 \\
\hline & Yeoju, Gyeonggi & Bed log & CNU N300 & HM769738 & HM920157 & HМ920186 \\
\hline & Yeoju, Gyeonggi & Sawdust & CNU N305 & HM769739 & HM920158 & HM920187 \\
\hline T. koningii & - & - & CBS 988.97 & DQ323409 & EU248600 & DQ289007 \\
\hline \multirow[t]{2}{*}{ T. longibrachiatum } & - & - & DAOM 166989 & EU330961 & EU338339 & EU338335 \\
\hline & Yecheon, Gyeongbuk & Bed log & CNU N086 & HM769753 & HM920172 & HM920201 \\
\hline \multirow[t]{3}{*}{ T. saturnisporum } & - & - & ATCC 28023 & X93977 & - & - \\
\hline & - & - & CBS 330.70 & - & DQ087243 & - \\
\hline & - & - & IMI 146852 & - & - & AY865642 \\
\hline T. scalesiae & - & - & G.J.S. 03-74 & DQ841742 & EU252007 & DQ841726 \\
\hline \multirow[t]{2}{*}{ T. strigosum } & - & - & CBS $348.93 \mathrm{~T}$ & AF487657 & - & - \\
\hline & - & - & DAOM 166121 & - & AF545556 & AF487668 \\
\hline T. tomentosum & - & - & DAOM178713A T & DQ085432 & AF545557 & AY750882 \\
\hline \multirow[t]{2}{*}{ T. virens } & - & - & G.J.S. 00-108 & DQ083023 & - & - \\
\hline & - & - & G.J.S. 01-287 & - & EU341804 & AY750894 \\
\hline T. viride & - & - & CBS 101526 & X93979 & EU248599 & AY376053 \\
\hline T. viridescens & - & - & CBS 333.72 & DQ315441 & EU341802 & DQ307523 \\
\hline
\end{tabular}


Table 1. Continued

\begin{tabular}{|c|c|c|c|c|c|c|}
\hline \multirow{2}{*}{ Species } & \multirow{2}{*}{ Locality } & \multirow{2}{*}{ Substrate } & \multirow{2}{*}{ Strain No. } & \multicolumn{3}{|c|}{ GenBank accession numbers } \\
\hline & & & & ITS & $r p b 2$ & tefl \\
\hline \multirow[t]{3}{*}{ Trichoderma sp. 1} & Yeoju, Gyeonggi & Sawdust & CNU N309 & HM769754 & HM920173 & HM920202 \\
\hline & Wanju, Jeonbuk & Sawdust & CNU N349 & HM769755 & HM920174 & HM920203 \\
\hline & Yeoju, Gyeonggi & Sawdust & CNU N417B & HM769756 & HM920175 & HM920204 \\
\hline \multirow[t]{2}{*}{ Trichoderma sp. 2} & Jangsu, Jeonbuk & Bed log & CNU N109 & HM769757 & HM920176 & HM920205 \\
\hline & Yeoju, Gyeonggi & Bed log & CNU N334 & HM769758 & HM920177 & HM920206 \\
\hline Hypocrea candida & - & - & CBS $114249 \mathrm{~T}$ & AY737757 & AY391899 & AY737742 \\
\hline H. catoptoron & - & - & CBS 114232 & AY737766 & AY391900 & AY737726 \\
\hline H. ceracea & - & - & CBS $114245 \mathrm{~T}$ & EU330953 & AF545508 & AY937437 \\
\hline H. ceramic & - & - & CBS $114576 \mathrm{~T}$ & AY737764 & AF545510 & AY737738 \\
\hline H. chlorospora & - & - & G.J.S. 98-1 & AY737762 & AY391906 & AY737737 \\
\hline H. cinnamomea & - & - & G.J.S. 97-237 & AY737759 & AY391920 & AY737732 \\
\hline H. cremea & - & - & CBS 111146 & AY737760 & AF545511 & AY737736 \\
\hline H. cuneispora & - & - & CBS 111148 & AY737763 & AF545512 & AY737727 \\
\hline \multirow[t]{2}{*}{ H. decipiens. } & - & - & G.J.S. 97-207 & EF558548 & - & EF550995 \\
\hline & - & - & G.J.S. 91-101 & - & DQ835520 & - \\
\hline H. dingleyae & - & - & CBS 119053 & DQ313151 & EU341803 & AF348117 \\
\hline H. intricate & - & - & G.J.S. 02-78 & EU264002 & EU241505 & EU248630 \\
\hline \multirow[t]{3}{*}{ H. jecorina } & - & - & TUB F-833 & AY857227 & - & - \\
\hline & - & - & TUB F-430 & - & DQ087241 & - \\
\hline & - & - & ATCC 24449 & - & - & DQ025754 \\
\hline H. melanomagna & - & - & CBS 114236 & AY737770 & AY391026 & AY737751 \\
\hline H. nigrovirens & - & - & CBS 114330 & AY737777 & AF545518 & AY737744 \\
\hline H. phyllostachydis & - & - & CBS 114071 & EU330959 & AF545513 & AY737745 \\
\hline H. rodmanii & - & - & G.J.S. 89-120 & EU330947 & EU338323 & EU338285 \\
\hline H. cf. rufa VE & - & - & IMI 352471 & EQ315449 & EU341808 & DQ307530 \\
\hline H. semiorbis & - & - & DAOM 167636 & AY737758 & AF545522 & AY737750 \\
\hline H. stilbohypoxyli & - & - & CBS 112888 & AY380915 & EU341805 & AY376062 \\
\hline H. straminea & - & - & CBS $114248 \mathrm{~T}$ & AY737765 & AY391945 & AY737746 \\
\hline H. thailandia & - & - & CBS 114234 & AY737772 & AY391957 & AY737748 \\
\hline H. victoriensis & - & - & G.J.S. 99-130 & EU330952 & EU338336 & EU338331 \\
\hline \multirow[t]{3}{*}{ Nectria cinnabarina* } & - & - & CBS 279.48 & AF163025 & - & - \\
\hline & - & - & G.J.S. 91-111 & - & AF545567 & - \\
\hline & - & - & G.J.S. 89-107 & - & - & AF543785 \\
\hline
\end{tabular}

*, out group; T, ex-type strain

deviation of the split frequencies dropped below 0.01 . The trees obtained before convergence was reached were discarded with the burn-in command, and the remaining trees were used to calculate a $50 \%$ majority consensus topology and PP. PP values below 0.95 were not considered significant. Model parameter summaries after MCMC run and burning first samples were collected. For combined sequences set mean substitution rates were estimated as $\mathrm{A} \leftrightarrow \mathrm{C}=0.09, \mathrm{~A} \leftrightarrow \mathrm{G}=0.34, \mathrm{~A} \leftrightarrow \mathrm{T}=0.10, \mathrm{C} \leftrightarrow \mathrm{G}=0.04$, $\mathrm{C} \leftrightarrow \mathrm{T}=0.38, \mathrm{G} \leftrightarrow \mathrm{T}=0.06$; nucleotide frequencies were estimated as $0.22(\mathrm{~A}), 0.29(\mathrm{C}), 0.24(\mathrm{G}), 0.25(\mathrm{~T})$; alpha parameter of gamma distribution shape was 0.65 .
Analysis of phenotypes. To check the cultural characteristics of the Trichoderma isolates, we selected eight representative of Trichoderma species ( $T$. harzianum CNU N169; T. atroviride CNU N088 and CNU N112; T. citrinoviride CNU N152 and CNU N153; T. longibrachiatum CNU N086; Trichoderma sp. 1 CNU N417B; and Trichoderma sp. 2 CNU N109), based on phylogenetic groupings (Fig. 1). The cultures used for the study of anamorph micromorphology were grown on cornmeal agar $+2 \%$ dextrose (CMD; Difco), synthetic low-nutrient agar (SNA; Nirenberg, 1976), or PDA (Difco) at $20^{\circ} \mathrm{C}$ or $25^{\circ} \mathrm{C}$ for $7-20$ days. All measurements for the morphological analyses were made 


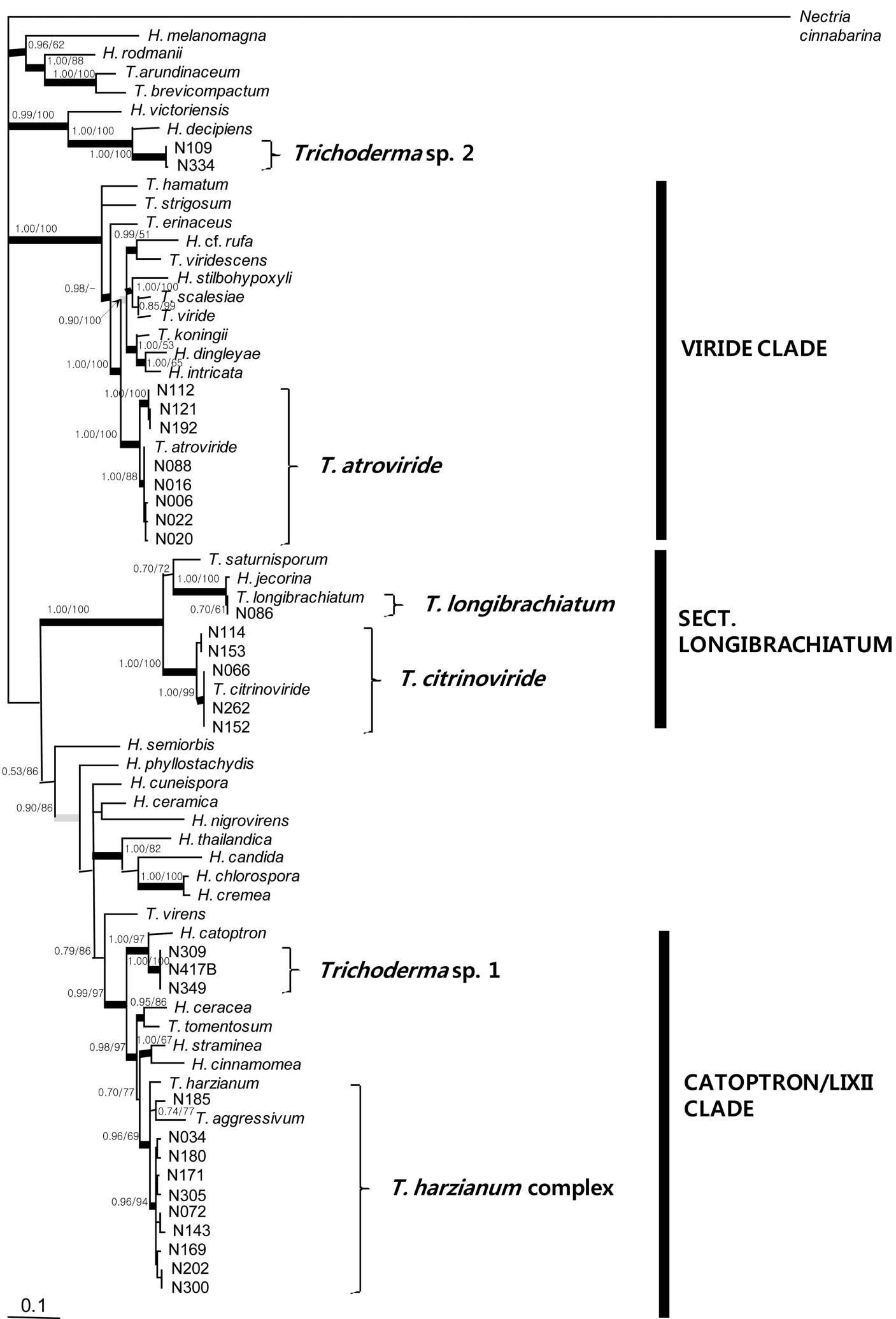

Fig. 1. Bayesian 50\% majority rule consensus topology based on the combined sequence set (ITS, rpb2, and tef1 genes). Bayesian posterior probabilities (PP), and bootstrap of 1000 replicates in NJ analysis are indicated as PP/NJBS above or below branches or at nodes. Only NJBS values $>50 \%$ are shown. Branching points supported by posterior probabilities $>0.94$ are indicated by thick lines, and those supported by $>0.89$ but $<0.95$ by gray lines. Nectria cinnabarina was used as the outgroup. 
in $3 \% \mathrm{KOH}$ or water. Where possible, 50 units of each morphological parameter were measured for each collection. Growth rates were determined on PDA and SNA. After a few days, when the colony growth was visible on PDA and SNA, but before conidia production, a plug (5 $\mathrm{mm}$ diameter) was taken from the actively growing edge of the colony and inoculated onto freshly prepared medium. The inoculum plug was placed mycelia-side-down, approximately $1 \mathrm{~cm}$ from the edge of a vented Petri dishes $(9 \mathrm{~cm}$ diameter) containing $20 \mathrm{ml}$ of freshly made medium. The Petri dishes were incubated in the dark at $15-45^{\circ} \mathrm{C}$ (in increments of $5^{\circ} \mathrm{C}$ ). They were examined at $24 \mathrm{~h}$ intervals when the colony radius, measured from the edge of the inoculum plug, and the colony appearance were recorded. Each growth trial consisted of a single Petri dish for each strain at each temperature. The growth trials were repeated three times at roughly weekly intervals, and the average radius was calculated from the three independent measurements.

Competition test. To assess the competition between the Lentinula edodes and Trichoderma species, we selected a shiitake mushroom race (Sanjo302) and six representative Trichoderma species (T. harzianum CNU N169, T. atroviride CNU N088, T. citrinoviride CNU N152, T. longibrachiatum CNU N086, Trichoderma sp. 1 CNU N417B, and Trichoderma sp. 2 CNU N109). On PDA, the shiitake inoculums were prepared 10 days before Trichoderma inoculation, and their appearance after invasion was observed 3, 10, and 15 days after Trichoderma species inoculation. To measure the growth rates and competition between the shiitake and Trichoderma species on sawdust medium, we modified the dual-culture method of Tokimoto et al. (1994). Glass tubes $(30 \mathrm{~mm}$ in diameter and $200 \mathrm{~mm}$ in length) were filled with the sawdust medium (oak sawdust and rice bran cakes in a ratio of $4: 1$; moisture content $=60 \%$ ), leaving $30 \mathrm{~mm}$ empty spaces at both ends. The ends of the glass tubes were capped with air-permeable silicon plugs. A $5 \mathrm{~mm}$ diameter disk of shiitake mycelia on PDA medium was inoculated at one end of the tube and allowed to grow at $25^{\circ} \mathrm{C}$ in the dark. Mycelial elongation $(\mathrm{mm})$ was measured from day 14 to day 21 . The other end of the tube was inoculated with a piece of Trichoderma species on day 21 . After incubation at $25^{\circ} \mathrm{C}$ for seven days, the extent of Trichoderma mycelial invasion into the mycelial block of shiitake was measured.

\section{Results}

Phylogenetic analysis. In the Bayesian inference a set of four chains reached convergence after about 3,000,000 generations, and therefore the first 30,000 trees in each parallel run were discarded by setting the burnin command to 30,000 ; the remaining ca. 40,002 trees (representing ca. $2,000,000$ generations) were used to calculate a $50 \%$ majority consensus tree and to determine PP. The likelihoods ( $\ln \mathrm{L}$ ) of the best states for cold chains of the two runs were -11710.30 and -11731.14 respectively.

The combined sequences (1366 total characters: 599 of ITS; 311 of rpb2; 456 of tefl) (Fig. 1) show the clear separation of these isolates with strong statistical support. The Trichoderma isolates were identified as T. harzianum, T. atroviride, T. citrinoviride, T. longibrachiatum, and two unidentified species, each of which were supported by high $\mathrm{PP}$ and BS values above 0.95 and $60 \%$. The isolated strains belong to section Longibrachiatum (T. longibrachiatum and $T$. citrinoviride), the Viride clade (T. atroviride), and the Catoptron/Lixii clade (T. harzianum and Trichoderma sp. 1), respectively. Trichoderma spp. 1 and 2 are closely related to Hypocrea catoptron and H. decipiens, respectively, but clearly differentiated from previously reported species of Trichoderma (Fig. 1).

Phenotypic analysis. The optimal temperature for the growth of all species on PDA or SNA was between $25^{\circ} \mathrm{C}$ and $30^{\circ} \mathrm{C}$. However, the mycelial growth rate can be useful in distinguishing Trichoderma species. Samuels et al. (2006) applied the system for growth rate determination to as many isolates of each species as possible using subtle differences in growth rate on PDA and SNA to aid in species delimitation. Fig. 2 shows growth rates of six species of Trichoderma on PDA and SNA media, given as $\mathrm{mm}$ colony radius after $72 \mathrm{~h}$ at seven temperatures. We found that the mycelial growth rate of Trichoderma sp. 1 was slow and its optimal temperature range was narrow compared with those of the other Trichoderma species. The optimal temperature range for Trichoderma sp. 2 was also narrow, but this species grew quickly at the optimal temperatures. The growth rate patterns of $T$. citrinoviride and $T$. longibrachiatum, belonging to section Longibrachiatum, were almost identical to each other, with a wide range at optimal temperatures (Fig. 2).

Differences in micromorphological characteristics of six species were described in Table 2 - Trichoderma spp. 1 and 2 compared with related species in phylogenetic tree, respectively. The morphological characteristics of four identified Trichoderma species (T. atroviride, T. citrinoviride, $T$. harzianum and T. longibrachiatum) were almost the same as those previously reported species by Park et al. (2005) (data not shown).

Optimum temperature of Trichoderma sp. 1 for growth on SNA and PDA ca. $20-25^{\circ} \mathrm{C}$. Colony radius on SNA after $3 \mathrm{~d}$ at $15^{\circ} \mathrm{C} 5.5-6.0 \mathrm{~mm}, 20^{\circ} \mathrm{C} 20.1-21.8 \mathrm{~mm}, 25^{\circ} \mathrm{C}$ $21.1-22.6 \mathrm{~mm}, 30^{\circ} \mathrm{C} 3.0-3.4 \mathrm{~mm}$ and $35-45^{\circ} \mathrm{C} 0.0 \mathrm{~mm}$ 

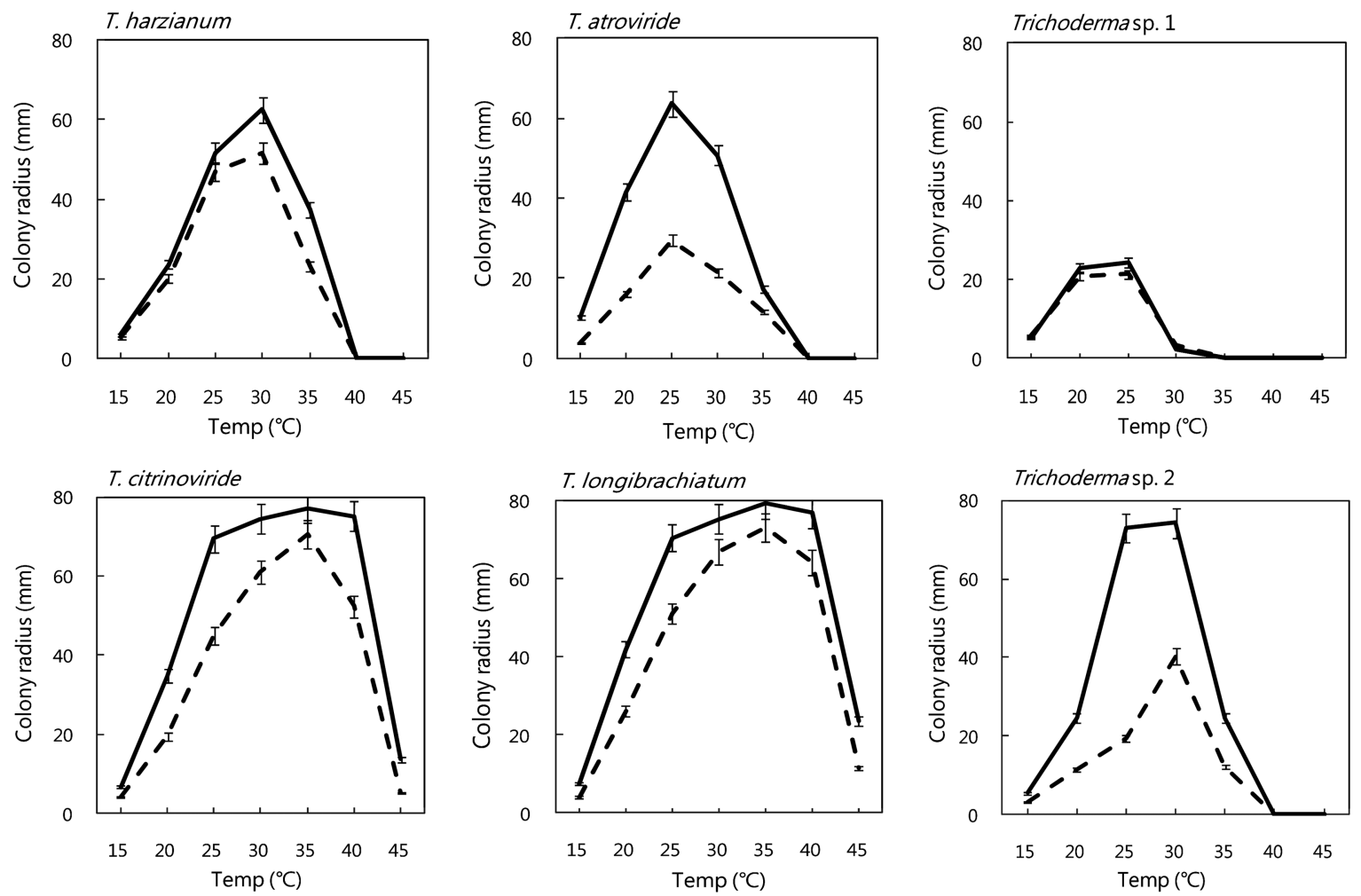

Fig. 2. Colony radii of Trichoderma species after 3 days on PDA or SNA at 15, 20, 25, 30, 35, 40, and $45^{\circ} \mathrm{C}$. Solid line $=$ PDA; dashed line $=$ SNA. Bars indicate the standard errors of the means of three replicate cultures.

Table 2. Morphological characteristics of six Trichoderma species and related species

\begin{tabular}{|c|c|c|c|c|c|}
\hline \multirow[b]{2}{*}{ Species } & \multicolumn{5}{|c|}{ Character } \\
\hline & $\begin{array}{l}\text { Conidiophore } \\
\text { type }\end{array}$ & $\begin{array}{l}\text { Phialides shape } \\
(\text { size: } \mu \mathrm{m})\end{array}$ & $\begin{array}{l}\text { Conidia shape } \\
\text { (size: } \mu \mathrm{m})\end{array}$ & $\begin{array}{l}\text { Coconut- } \\
\text { like odor }\end{array}$ & $\begin{array}{l}\text { Formation of } \\
\text { chlamydospores }\end{array}$ \\
\hline T. atroviride & trichoderma-like & $\begin{array}{l}\text { straight or sinuous, } \\
\text { sometimes hooked } \\
(5.8-14.3 \times 2.4-4.5)\end{array}$ & $\begin{array}{l}\text { subglobose to ovoidal } \\
(2.5-3.8 \times 2.1-3.3)\end{array}$ & + & + \\
\hline T. citrinoviride & $\begin{array}{l}\text { trichoderma- to } \\
\text { pachybasium-like }\end{array}$ & $\begin{array}{l}\text { cylindrical or } \\
\text { slightly enlarged } \\
(3.2-6.8 \times 2.1-3.3)\end{array}$ & $\begin{array}{l}\text { oblong to ellipsoidal } \\
(2.1-3.5 \times 1.4-2.1)\end{array}$ & - & + \\
\hline T. harzianum & pachybasium-like & $\begin{array}{l}\text { flask-shaped } \\
(3.3-7.2 \times 2.3-3.7)\end{array}$ & $\begin{array}{l}\text { subglobose to ovoidal } \\
(2.4-3.6 \times 1.8-2.8)\end{array}$ & - & + \\
\hline T. longibrachiatum & trichoderma-like & $\begin{array}{l}\text { cylindrical } \\
(4.9-12.2 \times 1.9-3.4)\end{array}$ & $\begin{array}{l}\text { oblong to ellipsoidal } \\
(3.4-5.9 \times 2.3-3.4)\end{array}$ & - & + \\
\hline Trichoderma sp. 1 & $\begin{array}{l}\text { verticillium- to } \\
\text { gliocladium-like }\end{array}$ & $\begin{array}{l}\text { ampulliform or lageniform } \\
(4.0-12.9 \times 1.3-3.5)\end{array}$ & $\begin{array}{l}\text { ellipsoidal to rare reniform } \\
(2.3-5.2 \times 1.8-3.0)\end{array}$ & - & + \\
\hline $\begin{array}{l}\text { Hypocrea catoptron/ } \\
\text { T. catoptron* }\end{array}$ & $\begin{array}{l}\text { pachybasium- to } \\
\text { verticillium-like }\end{array}$ & $\begin{array}{l}\text { ampulliform } \\
(5.5-7.2 \times 3.2-4.2)\end{array}$ & $\begin{array}{l}\text { ellipsoidal to oblong } \\
(3.5-4.0 \times 2.3-2.7)\end{array}$ & - & - \\
\hline H. straminea* & $\begin{array}{l}\text { pachybasium- to } \\
\text { verticillium-like }\end{array}$ & $\begin{array}{l}\text { ampulliform } \\
(2.7-5.0 \times 3.0-5.0)\end{array}$ & $\begin{array}{l}\text { broad ellipsoidal, } \\
\text { sometimes oblong } \\
(3.0-3.2 \times 2.0-2.2)\end{array}$ & - & - \\
\hline Trichoderma sp. 2 & NA & NA & NA & - & + \\
\hline H. decipiens** & $\begin{array}{l}\text { irregularly } \\
\text { verticillate }\end{array}$ & $\begin{array}{l}\text { subulate } \\
(13-25 \times 2.4-3.0)\end{array}$ & $\begin{array}{l}\text { subglobose or obovate to } \\
\text { subellipsoidal } \\
(4.4-6.7 \times 2.5-3.5)\end{array}$ & ND & ND \\
\hline
\end{tabular}

+ , detected; -, not detected; NA, not available due to lack of conidia; ND, not described

*, Chaverri and Samuels, 2003

**, Overton et al., 2006 (H. decipiens for the species interpreted as H. farinosa) 


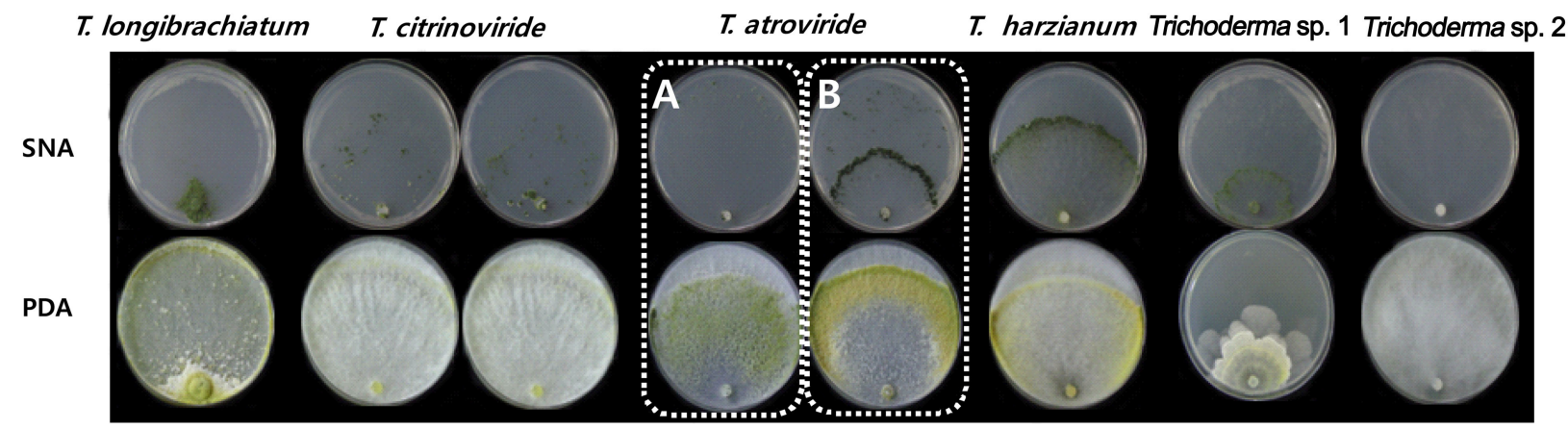

Fig. 3. Culture of Trichoderma species on SNA and PDA media for 10 days at $25^{\circ} \mathrm{C}$. A, T. atroviride strain CNU N112; B, T. atroviride strain CNU N088.
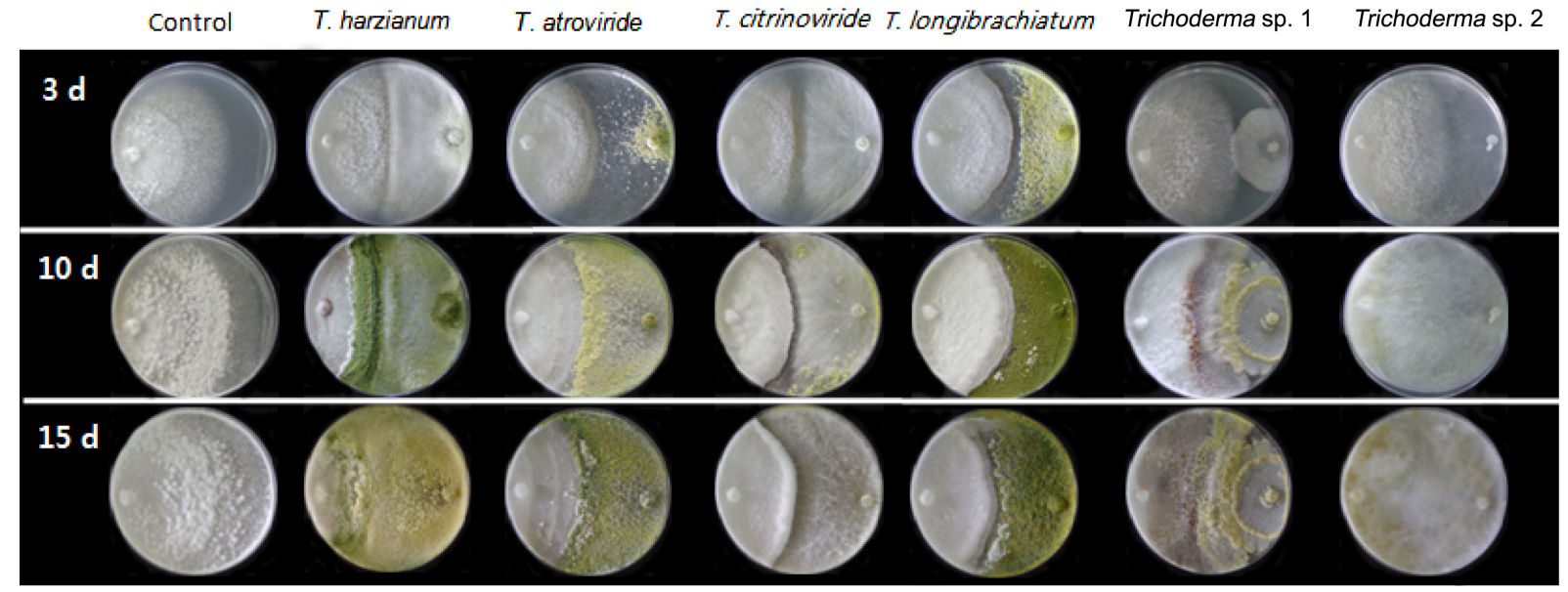

Fig. 4. Dual cultures of Lentinula edodes (Sanjo 302) and Trichoderma species on PDA at $25^{\circ} \mathrm{C}$. The shiitake mycelium inoculums were prepared 10 days before the Trichoderma inoculation and their invaded appearance was observed after 3, 10, and 15 days. Cultures of $L$. edodes were controls on left side (on PDA at $25^{\circ} \mathrm{C}$ ).

$(\mathrm{n}=3)$. Colony radius on PDA after $3 \mathrm{~d}$ at $15^{\circ} \mathrm{C} 4.9-5.5 \mathrm{~mm}$, $20^{\circ} \mathrm{C} 16.7-20.1 \mathrm{~mm}, 25^{\circ} \mathrm{C} 17.3-25.2 \mathrm{~mm}, 30^{\circ} \mathrm{C} 2.1-3.0$ $\mathrm{mm}$ and $35-45^{\circ} \mathrm{C} 0.0 \mathrm{~mm}(\mathrm{n}=3)$ (Fig. 2). On SNA at $25^{\circ} \mathrm{C}$ for $10 \mathrm{~d}$, colony formed a curcular band of light green and pustules. On PDA at $25^{\circ} \mathrm{C}$ for $10 \mathrm{~d}$, mycelia growth pattern were irregular appearance (Fig. 3). No odor detected. Conidia ellipsoidal to rare reniform, smooth, 2.3-5.2 × 1.8$3.0 \mu \mathrm{m}, \mathrm{L} / \mathrm{W}$ ratio of 1.0-2.4. Chlamydospores formed. Conidiophores type veticillium- to gliocladium-like, and phialides shape ampulliform or lageniform, 4.0-12.9 $\times$ $1.2-3.5 \mu \mathrm{m}, \mathrm{L} / \mathrm{W}$ ratio of $1.8-5.2$.

Optimum temperature of Trichoderma sp. 2 for growth on SNA ca. $30^{\circ} \mathrm{C}$ and on PDA $25-30^{\circ} \mathrm{C}$. Colony radius on SNA after $3 \mathrm{~d}$ at $15^{\circ} \mathrm{C} 2.1-5.7 \mathrm{~mm}, 20^{\circ} \mathrm{C} 8.4-14.5 \mathrm{~mm}$, $25^{\circ} \mathrm{C} 15.2-23.7 \mathrm{~mm}, 30^{\circ} \mathrm{C} 36.4-53.1 \mathrm{~mm}, 35^{\circ} \mathrm{C} 11.3-13.0$ and $40-45^{\circ} \mathrm{C} 0.0 \mathrm{~mm}(\mathrm{n}=3)$. Colony radius on PDA after $3 \mathrm{~d}$ at $15^{\circ} \mathrm{C} 5.2-5.7 \mathrm{~mm}, 20^{\circ} \mathrm{C} 22.6-26.4 \mathrm{~mm}, 25^{\circ} \mathrm{C} 72.7-$ $73.6 \mathrm{~mm}, 30^{\circ} \mathrm{C} 73.7-75.8 \mathrm{~mm}, 35^{\circ} \mathrm{C} 18.8-30.2$ and $40-$ $45^{\circ} \mathrm{C} 0.0 \mathrm{~mm}(\mathrm{n}=3)$ (Fig. 2). On SNA and PDA at $25^{\circ} \mathrm{C}$ for $10 \mathrm{~d}$, did not produce spore, but only white mycelial growth
(Fig. 3). No odor detected.

Competition between Lentinula edodes and Trichoderma species. The competition test between the Lentinula edodes (Sanjo 302) and Trichoderma species indicated that the six species of Trichoderma were significantly different from each other in terms of their ability to invade the mycelial blocks of shiitake on PDA (Fig. 4). Of the Trichoderma species, Trichoderma spp. 1 and 2 and T. harzianum had strongly invaded the mycelial blocks of shiitake 15 days after Trichoderma inoculation. In contrast, T. atroviride had only moderately invaded the mycelial blocks of shiitake, and T. citrinoviride and T. longibrachiatum had only slightly invaded them or not at all.

The growth rate of Trichoderma species and L. edodes were investigated on sawdust medium. The growth of the Trichoderma species was approximately 3-5 times faster than that of the shiitake mycelia (Fig. 5). Among the Trichoderma species, the growth rate of Trichoderma sp. 2 was faster than those of the other species, whereas that of 


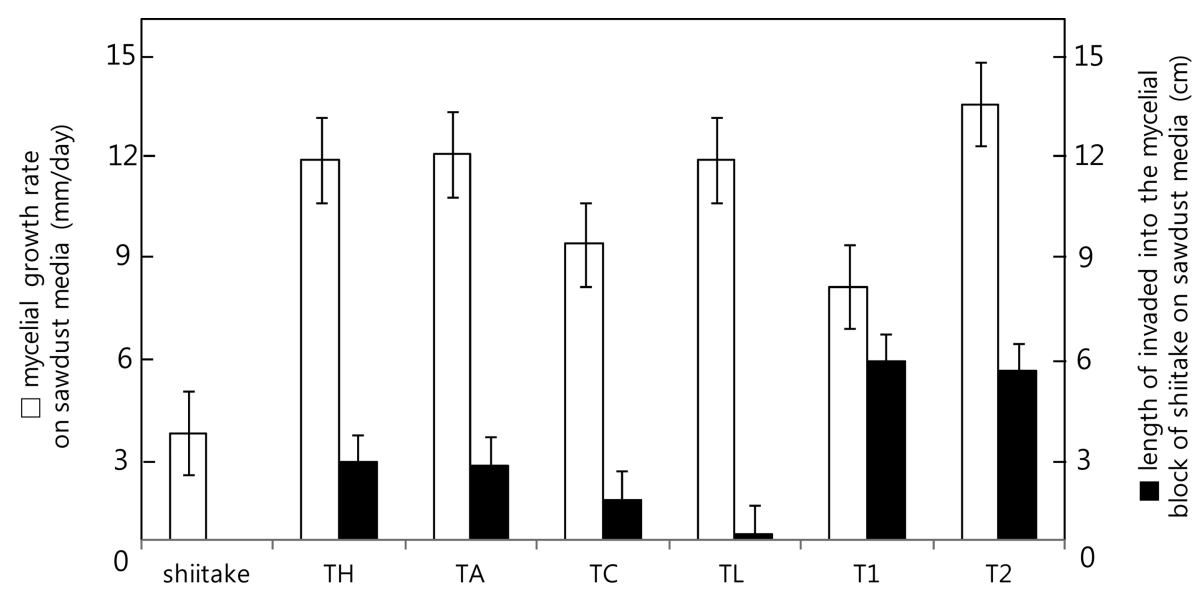

Fig. 5. Growth rate of Lentinula edodes (Sanjo 302) and Trichoderma species at $25^{\circ} \mathrm{C}$ on sawdust medium (left). Distance of Trichoderma species invasion into the mycelial block of shiitake, seven days after Trichoderma species inoculation in dual culture in sawdust medium at $25^{\circ} \mathrm{C}$ (right). TH, T. harzianum; TA, T. atroviride; TC, T. citrinoviride; TL, T. longibrachiatum; T1, Trichoderma sp. 1; T2, Trichoderma sp. 2. Bars indicate the standard errors of the means of three replicates.

Trichoderma sp. 1 was slowest. In the competition test on sawdust medium, Trichoderma spp. 1 and 2 strongly invaded the mycelial blocks of shiitake, and T. harzianum and $T$. atroviride moderately invaded them. However, T. citrinoviride and T. longibrachiatum invaded the mycelial blocks of shiitake only slightly or not at all (Fig. 5).

\section{Discussion}

Six species of Trichoderma were clearly distinguished in the present phylogenetic and phenotypic analyses. Nine Trichoderma species that cause economic losses during shiitake cultivation have previously been reported in Japan [T. atroviride, T. citrinoviride, T. harzianum, T. longibrachiatum, T. pseudokoningii, T. polysporum, T. cf. stramineum, T. virens and Trichoderma sp. (Miyazaki et al., 2009)]. However, we found only six species: T. harzianum, $T$. atroviride, T. citrinoviride, T. longibrachiatum, and two unidentified species. We speculate that still many additional species will be recognized in Korea.

Recently, Kim et al. (2010) reported Gliocladium viride (anamorph of Hypocrea lutea), isolated from bedlogs of shiitake mushroom. This species damaged to bedlogs of shiitake mushroom and were infested by mushroom flies. Although this species was morphologically similar to true Gliocladium, its phylogenetic position located in Hypocreal Trichoderma, and teleomoph characteristics of this species is an undoubted species of Hypocrea (Samueals, 2006). For that reasons, the scientific name of this species was changed to Trichoderma deliquescens by Jaklitsch (2011).

Trichoderma sp. 1 is phylogenetically related to Hypocrea catoptron, but the two species could be easily distinguished by the branching pattern of the conidiophores; in the former species it is veticillium- to gliocladium-like, but in latter is pachybasium-like. In comparison of ITS sequences, this species was identical to a sequence of $T$. cf. stramineum (GenBank Accession No. AB298692), but we could find no morphological description of the latter isolate. However, the ex-type of $H$. straminea CBS 114248 (anamorph: $T$. stramineum) and Trichoderma sp. 1 are distantly related in phylogenetic tree (see Fig. 1). Morphologically, H. straminea CBS114248 (ex-type) is also clearly different from Trichoderma sp. 1 by forming pachybasium- and verticillium-like conidiophores, and by producing no chlamydospores on the medium, along with $H$. catoptron (Table 2). Therefore, Trichoderma sp. 1 remains an unidentified species.

The phylogenetic position of Trichoderma sp. 2 is close to $H$. decipiens, but they were clearly divided into two groups in combined tree (Fig. 1) and their individual gene trees also supported that (data not shown). Interestingly, the isolates of Trichoderma sp. 2 did not produce conidia on SNA, PDA, or CMD medium, and chlamydospores were only produced by an old colony on PDA medium. Trichoderma section Hypocreanum is characterized by verticilliumand acremonium-like anamorphs (Chaverri and Samuels, 2003). However, these anamorphs are difficult to find and sometimes they do not produce conidia on artificial medium. Previously, Kullnig-Gradinger et al. (2002) suggested that during its evolution, Trichoderma sect. Hypocreanum may have lost the ability to form Trichoderma-like anamorphs. For that reason, Trichoderma sp. 2 may be belongs to sect. Hypocreanum.

Phylogenetic analysis (Fig. 1) revealed the genetic variations within $T$. harzianum. It was well known from a report of Chaverri et al. (2003) that the T. harzianum-H. lixii species complex consists of several phylogenetic line- 
ages. Trichoderma citrinoviride and T. atroviride are separated into two subgroups on the tree, but they share almost identical morphological characteristics (data not shown). Interestingly, we noted also genetic variation within T. atroviride (Fig. 1). In Fig. 1, T. atroviride was slightly divided into two groups: group A (N112, N121 and N192) and group B (N006, N016, N020, N022 and N088). These two groups could be distinguished on SNA medium. Group B formed a circular band of dark green with pustules, but group A did not form it (Fig. 3). This character allows the easy distinction of the two groups. Apart from this exception, their morphological characteristics are similar and they are phylogenetically closely related. Therefore, we consider that these groups belong to a species, with accumulating genetic variations.

Most Trichoderma species can secrete lytic enzymes (mainly 13-1,3-glucanases and chitinases) or antibiotics that inhibit the cell wall synthesis of other fungi (Chet, 1987; Claydon et al., 1987; Dennis and Webster, 1971a, b; Di Pietro et al., 1993; Howell, 1998; Schirmbock et al., 1994). For example, T. atroviride has a coconut-like odor attributed to 6-pentyl-a-pyrone (6PAP) that inhibits spore germination of plant pathogenic fungi and suppresses the mycelial growth of other fungi (Smith and Grula, 1982; Stefanova et al., 1999). In the present competition test, Trichoderma spp. 1 and 2 caused severe damage to the mycelia of the shiitake. These results suggest a possibility that they secrete powerful lytic enzymes or antibiotics. We hope to find new lytic enzymes or antibiotics in these species.

\section{Conclusion}

Of six species of Trichoderma associated with the green mold observed during shiitake mushroom cultivation, three species are newly reported as shiitake mushroom competitors in Korea: T. atroviride and two previously unknown species (Trichoderma spp. 1 and 2). Based on their molecular and morphological characteristics, we propose the two unidentified species as the candidate of new species. Given the result of competitive tests, Trichoderma spp. 1 and 2 could potentially cause large economic crop losses in shiitake mushroom cultivation. Therefore, more extensive research is required in the near future.

\section{Acknowlegements}

We are so grateful to reviewers and editors for their comments and proofreadings on the manuscript. This work was supported by a grant from Regional Subgenebank Support Program of Rural Development Administration, Republic of Korea.

\section{References}

Anonymous. 2009. List of Plant Diseases in Korea. $5^{\text {th }}$ Edition. The Korean Society of Plant Pathologly, Seoul. 853 pp..

Bissett, J. 1984. A revision of the genus Trichoderma. I. Sect. Longibrachiatum sect. nov. Can. J. Bot. 62:924-931.

Bissett, J. 1991a. A revision of the genus Trichoderma. II. Infrageneric classificaition. Can. J. Bot. 69:2357-2372.

Bissett, J. 1991b. A revision of the genus Trichoderma. III. Sect. Pachybasium. Can. J. Bot. 69:2373-2417.

Bissett, J. 1991c. A revision of the genus Trichoderma. IV. Additional notes on section Longibrachiatum. Can. J. Bot. 69: 2418-2420.

Carbone, I. and Kohn, L. M. 1999. A method for designing primer sets for speciation studies in filamentous ascomycetes. Mycologia 91:553-556.

Chaverri, P. and Samuels, G. J. 2003. Hypocrea/Trichoderma (Ascomycota, Hypocreales, Hypocreaceae): species with green ascospores. Stud. Mycol. 48:1-113.

Chen, A. W. 2005. Chapter 1: What is shiitake. In: Mushroom Growers' Handbook 2. ed. by MushroomWorld. pp. 1-11. MushroomWorld, Seoul, Korea.

Chet, I. 1987. Trichoderma - application, mode of action and potential as a biocontrol agent of soil borne plant pathogenic fungi. In: Innovative Approaches to Plant Disease Control, ed. by I. Chet, pp.137-160. John Wiley and Sons, New York, USA.

Chun, J. 1995. Computer-assisted classification and identification of actinomycetes. Ph. D. thesis, University of Newcastle, Newcastle upon Tyne, UK.

Claydon, N., Allan, M., Hanso, J. R. and Avent, A. G. 1987. Antifungal alkyl pyrones of Trichoderma harzianum. Trans. Br. Mycol. Soc. 88:503-513.

Cubero, O. F., Crespo, A. N. A., Fatehi, F. and Bridge, P. D. 1999. DNA extraction and PCR amplification method suitable for fresh, herbarium-stored, lichenized, and other fungi. Pl. Syst. Evol. 216:243-249.

Degenkolb, T., Dieckmann, R., Nielsen, K. F., Gräfenhan, T., Theis, C., Zafari, D., Chaverri, P., Ismaiel, A., Brückner, H., Döhren, von H., Thrane, U., Petrini, O. and Samuels, G. J. 2008. The Trichoderma brevicompactum clade: a separate lineage with new species, new peptibiotics, and mycotoxins. Mycol. Progr. 7:177-219.

Dennis, C. and Webster, J. 1971a. Antagonistic properties of species groups of Trichoderma. I. Production of nonvolatile antibiotics. Trans. Br. Mycol. Soc. 57:25-39.

Dennis, C. and Webster, J. 1971b. Antagonistic properties of species groups of Trichoderma. II. Production of volatile antibiotics. Trans. Br. Mycol. Soc. 57:41-48.

Di Pietro, A., Lorito, M., Hayes, C., Broadway, K. and Harman, G. E. 1993. Endochitinase from Gliocladium virens. Isolation, characterization, synergistic antifungal activity in combination with gliotoxin. Phytopathology 83:308-313.

Hashioka, Y. 1973. Scanning electronmicroscopy on the mycoparasites, Trichoderma, Gliocladium and Acremonium. Rept. Tottori Mycol. Inst. 10:473-484. 
Howell, C. R. 1998. The role of antibiosis in biocontrol. In: Trichoderma \& Gliocladium, vol. 2. ed. by G.E. Harman and C. P. Kubicek, pp 173-184. Taylor \& Francis, Padstow.

Jaklitsch, W. M. 2009. European species of Hypocrea Part I. The green-spored species. Stud. Mycol. 63:1-91.

Jaklitsch, W. M. 2011. European species of Hypocrea part II: species with hyaline ascospores. Fungal Divers. 48:1-250.

Jeon, Y.-A., Kim, W.-G., Kim, D.-H., Kwon, S.-W. and Hong, S. B. 2010. Taxonomic position of Korean isolates of Rhizoctonia solani based on RAPD and ITS sequencing of ribosomal DNA. Plant Pathol. J. 26:83-89.

Kim, J. Y., Yun, Y. H., Hyun, M. W., Kim, M. H. and Kim, S. H. 2010. Identification and characterization of Gliocladium viride isolated from mushroom fly infested oak log used for shiitake cultivation. Mycobiology 38:7-12.

Kim, J. Y., Kwon, H. W., Tang, L. and Kim, S. H. 2012. Identification and characterization of Trichoderma citrinoviride isolated from mushroom fly-infested oak log beds used for shiitake cultivation. Plant Pathol. J. 28:219.

Kullnig-Gradinger, C. M., Szakacx, G. and Kubicek, C. P. 2002. Phylogeny and evolution of the fungal genus Trichoderma - a multigene approach. Mycol. Res. 106:757-767.

Lieckfeldt, E. and Seifert, K. A. 2000. An evaluation of the use of ITS sequences in the taxonomy of the Hypocreales. Stud. Mycol. 45:35-44.

Liu, Y. J., Whelen, S. and Hall, B. D. 1999. Phylogenetic Relationships Among Ascomycetes: Evidence from an RNA polymerase II Subunit. Mol. Biol. Evol. 16:1799-1808.

Luo, X. C. 2004. Progress of xiang-gu (shiitake) cultivation in China. In: Mushroom Science XVI: Science and Cultivation of Edible and Medicinal Fungi. ed. by Romaine, Keil, Rinker and Royes, pp. 317-322. The Pennsylvania State University Press, USA.

Miyazaki, K. and Tsunoda, M. 2003. Application of DNA markers to research on Trichoderma in mushroom facilities of Japan (1): RAPD, SSCP marker. Mushroom Sci. Biotechnol. 11:65-70.

Miyazaki, K., Tsuchiya, Y. and Okuda, T. 2009. Specific PCR assays for the detection of Trichoderma harzianum causing green mold disease during mushroom cultivation. Mycoscience 50:94-99.

Nirenberg, H. I. 1976. Untersuchungen über die morphologische und biologische Differnzierung in der Fusarium-Sektion Liseola. Mitteilungen aus der Biologischen Bundesanstalt für Land- und Forstwirtschaft Berlin- Dahlem 169:1-117.

O'donnell, K., Cigelnik, E. and Nirenberg, H. I. 1998. Molecular systematic and phylogeography of the Gibberella fujikuroi species complex. Mycologia 90:465-493.

Overten, B. E., Stewart, E. L. and Geiser, D. M. 2006. Taxonomy and phylogenetic relationships of nine species of Hypocrea with anamorphs assignable to Trichoderma section Hypocreanum. Stud. Mycol. 56:39-65.

Park, M. S., Seo, G. S., Lee, K. H., Bae, K. S. and Yu, S. H. 2005. Morphological and cultural characteristics of Trichoderma spp. associated with green mold of oyster mushroom in Korea. Plant Pathol. J. 21:221-228.
Park, M. S., Bae, K. S. and Yu, S. H. 2006. Two new species of Trichoderma associated with green mold of oyster mushroom cultivation in Korea. Mycobiology 34:111-113.

Rifai, M. A. 1969. A revision of the genus Trichoderma. Mycol. Pap. 116:1-116.

Ronquist, F. and Huelsenbeck, J. P. 2003. MrBayes 3: Bayesian phylogenetic inference under mixed models. Bioinformatics 19:1572-1574.

Samuels, G. J., Petrini, O., Kuhls, K., Lieckfeldt, E. and Kubicek, C. P. 1998. The Hypocrea schweinitzii complex and Trichoderma sect. Longibrachiatum. Stud. Mycol. 41:1-54.

Samuels, G. J., Gams, W., Castlebury, L. A. and Petrini, O. 2002. Trichoderma species associated with the green mold epidemic of commercially grown Agaricus bisporus. Mycologia 94: 146-170.

Samuels, G. J. 2006. Trichoderma: Systematics, the sexual state, and ecolgy. Phytopathology 96:195-206.

Samuels, G. J., Dodd, S., Lu, B., Petrini, O., Schroers, H. and Druzhinina I. S. 2006. The Trichoderma koningii aggregate species. Stud. Mycol. 56:67-133.

Schirmbock, M., Lorito, M., Wang, Y. L., Hayes, C. K., ArisanAtac, I., Scala, F., Harman, G. E. and Kubicek, C. P. 1994. Parallel formation and synergism of hydrolytic enzymes and peptaibol antibiotics, molecular mechanisms involved in the antagonistic action of Trichoderma harzianum against phytopathogenic fungi. Appl. Environ. Microbiol. 60:4364-4370.

Smith, R. J. and Grula, E. A. 1982. Toxic components on the larval surface of the corn earworm (Heliothis zea) and their effects on germination and growth of Beauveria bassiana. $J$. Invertebr. Pathol. 39:15-22.

Stefanova, M., Leiva, A., Larrinaga, L. and Coronado, M. F. 1999. Metabolic activity of Trichoderma spp. isolates for a control of soil-borne phytopathogenic fungi. Revista de la Facultad de Agronomia, Universidad del Zulia 16:509-516.

Swofford, D. L. 2003. PAUP*: phylogenetic analysis using parsimony (*and other methods). Version 4.0b10. Sunderland, Massachusetts: Sinauer Associates.

Taylor, J. W., Jacobson, D. J. and Fisher, M. 1999. The evolution of asexual fungi: speciation and classification. Annu. Rev. Phytopathol. 37:197-246.

Thompson, J. D., Gibson, T. J., Plewniak, F., Jeanmougin, F. and Higgins, D. G. 1997. The ClustalX windows interface: flexible strategies for multiple sequence alignment aided by quality analysis tools. Nucleic Acids Res. 25:4876-4882.

Tokimoto, K. and Komatsu, M. 1975. Effect of carbon and nitrogen sources in media on the hyphal interference between Lentinus edodes and some species of Trichoderma. Ann. Phytopathol. Soc. Jpn. 45:261-264.

Tokimoto, K. 1985. Physiological studies on antagonism between Lentinus edodes and Trichoderma spp. in bedlogs of the former (in Japanese). Rep. Tottori Mycol. Inst. 23:1-54.

Tokimoto, K., Komatsu, M. and Fukumasa-nakai, Y. 1994. Establishing the selection method for the Lentinula edodes strains resistant to Trichoderma spp. Proc. Japan Acad. 70:112-116.

Watanabe, S., Kumakura, K., Kato, H., Iyozumi, H., Togawa, M. and Nagayama, K. 2005. Identification of Trichoderma SKT- 
1, a biological control agent against seedborne pathogens of rice. J. Gen. Plant Pathol. 71:351-356.

White, T. J., Bruns, T. D., Lee, S. B. and Taylor, J. W. 1990. Amplification and direct sequencing of fungal ribosomal DNA for phylogenetics. In: PCR protocols: A guide to the methods and applications. ed. by M. A. Innes, D. H. Gelfand, J. J. Sninsky and T. J. White, pp. 315. Academic Press, New
York, USA.

Yamamoto, Y., Shirono, H., Kono, K. and Ohashi, Y. 1997. Immunopotentiating activity of the water-soluble lignin rich fraction prepared from LEM--the extract of the solid culture medium of Lentinus edodes mycelia. Biosci. Biotechnol. Biochem. 61:1909-1912. 